\title{
VARIAÇÕES ESTRUTURAIS E AMBIENTAIS EM UM CONTÍNUO DE MATA DE GALERIA/CERRADO STRICTO SENSU EM ITUMIRIM, MG
}

\author{
Ricardo Ayres Loschi ${ }^{1}$, José Aldo Alves Pereira², Evandro Luiz Mendonça Machado 3 , Leandro Carlos ${ }^{4}$, \\ Anne Priscila Dias Gonzaga ${ }^{5}$, Isaias Paulino Carmo ${ }^{6}$, Danilo José Santos Gomes ${ }^{7}$
}

(recebido: 4 de março de 2011; aceito: 25 de janeiro de 2013)

\begin{abstract}
RESUMO: Objetivou-se, com este trabalho, verificar as possíveis correlações entre as variações da estrutura, da diversidade de espécies e de variações do substrato num compartimento arbóreo em um contínuo de Mata de Galeria/Cerrado stricto sensu em Itumirim, sul de Minas Gerais. Os solos das áreas de Mata de Galeria, transição e Cerrado stricto sensu apresentaram textura média, acidez elevada com pH entre 4,5 e 5,0 e altos teores de alumínio. O levantamento estrutural em todo o fragmento apresentou 1.347 indivíduos que se distribuíram em 39 famílias, 77 gêneros e 102 espécies. A família Fabaceae destacou-se pela maior riqueza de espécies seguida das famílias Myrtaceae, Lauraceae e Rubiaceae. As espécies Protium spruceanum e Myrsine umbellata foram superiores em todos os parâmetros fitossociológicos, respectivamente, para as áreas de Mata de Galeria e Cerrado stricto sensu. Na área de transição, a espécie Copaifera langsdorffii obteve os maiores valores de área basal e dominância absoluta; já, com relação à densidade absoluta e valor de cobertura foi a espécie Myrsine umbellata. Os índices de diversidade de Shannon (H') e os índices de equabilidade de Pielou (J') para os três ambientes foram de 3,57, 3,51 e 2,58 e 0,79, 0,88 e 0,77, respectivamente, para as áreas de Mata de Galeria, transição e Cerrado stricto sensu. Por meio da análise de correspondência retificada (DCA) observaram-se dois agrupamentos no diagrama da DCA: Agrupamento 1, contendo apenas as três parcelas pertencentes ao Cerrado stricto sensu; Agrupamento 2, reunindo as demais parcelas amostradas abrangendo os ambientes de Mata de Galeria e transição.
\end{abstract}

Palavras-chave: Gradiente savana-floresta, estrutura do compartimento arbóreo, diversidade, relações solo-vegetação, fragmentação florestal.

\section{STRUCTURAL AND ENVIRONMENTAL VARIATIONS IN A CONTINUUM OF GALLERY FOREST/SAVANA STRICTO SENSU IN ITUMIRIM, MG}

\begin{abstract}
This work verified the possible correlations among the variations of the strucuture, species diversity and variations of the substrate in a tree compartment in a continuum of Gallery Forest/Savana stricto sensu in Itumirim, southern of Minas Gerais. The soils of the areas of Gallery Forest, Transition Forest and Savana stricto sensu presented medium structure, high acidity with pH between 4.5 and 5.0 and high aluminum contents. The structural survey all over the patch presented 1,347 individuals distributed into 39 families, 77 genera and 102 species. The family Fabaceae stood out by the greatest richness of species followed by the families Myrtaceae, Lauraceae and Rubiaceae. The species Protium spruceanum and Myrsine umbellata were superior in all the phytosociological parameters, respectively, for all the areas of Gallery Forest and Savana stricto sensu. In the area of transition, the species Copaifera langsdorffi reached the highest values of basal area and absolute dominance; however, as regards to absolute density and cover value was the species Myrsine umbellata. Shannon's diversity indices ( $H$ ') and Pielou's equatibility index ( $J$ ') for the three places were of 3,57,3,51 and 2,58 and 0,79, 0,88 and 0,77, respectively, for the areas of Gallery Forest, transition Forest and Savana stricto sensu. Through the rectified correspondence analysis (DCA), two groupings in the DCA diagram were found: grouping 1 containing only the three plots corresponding to the Savana stricto sensu; and grouping 2 joining together the other plots sampled encompassing the sites of Gallery and transition Forest.
\end{abstract}

Key words: Savanna-florest gradient, tree compartment strucuture, diversity, soil-vegetation relationships, forest fragmentation.

${ }^{1}$ Engenheiro Florestal, Mestre em Engenharia Florestal - Universidade Federal de Lavras/UFLA -Departamento de Ciências Florestais/DCF - Cx. P. 3037 - 37200-000 - Lavras, MG, Brasil-riloschi@gmail.com

${ }^{2}$ Engenheiro Florestal, Professor Dr. em Ecologia - Universidade Federal de Lavras/UFLA -Departamento de Ciências Florestais/DCF - Cx. P. 3037 37200-000 - Lavras, MG, Brasil-j.aldo@dcf.ufla.br

${ }^{3}$ Engenheiro Florestal, Professor Dr. em Ecologia - Universidade Federal dos Vales do Jequitinhonha e Mucuri/UFVJM - Departamento de Engenharia Florestal /DEF - Cx. P. 049 - 39100-000 - Diamantina, MG, Brasil-machadoelm@gmail.com

${ }^{4}$ Engenheiro Florestal, Doutorando em Engenharia Florestal - Universidade Federal de Lavras/UFLA -Departamento de Ciências Florestais/DCF Cx. P. 3037 - 37200-000 - Lavras, MG, Brasil - 1cmaestro@gmail.com

${ }_{5}^{5}$ Bióloga, Doutoranda em Ciências Florestais - Universidade Federal de Brasília/UnB - Departamento de Engenharia Florestal/DEF - Cx. P. 04357 70919-970 - Brasília, DF, Brasil - diaspri@gmail.com

${ }^{6}$ Engenheiro Florestal, Mestrando em Engenharia Florestal - Universidade Federal de Lavras/UFLA -Departamento de Ciências Florestais/DCF Cx. P. 3037 -37200-000 - Lavras, MG, Brasil - isaiaspaulino@gmail.com

${ }^{7}$ Engenheiro Agrônomo - Universidade Federal de Lavras/UFLA - Departamento de Agricultura /DAG -Cx. P. 3037 - $37200-000$ - Lavras, MG, Brasil-agrogomes@gmail.com

Cerne, Lavras, v. 19, n. 2, p. 213-227, abr./jun. 2013 


\section{INTRODUÇÃO}

A vegetação primitiva da região do Alto Rio Grande, ao sul de Minas Gerais, compreendia um complexo mosaico composto de manchas de floresta, cerrado, campo de altitude e campo rupestre (EITEN, 1982). Tal variação deve-se, principalmente, ao fato de a região abrigar uma das áreas de transição entre os cerrados do Brasil Central e as florestas semidecíduas do Domínio Atlântico, transição esta que ocorre nas acidentadas vertentes continentais da serra da Mantiqueira, o que incrementa a heterogeneidade ambiental e, por conseguinte, também a biológica (OLIVEIRA-FILHO et al., 1994b).

Alguns estudos mostram que a vegetação do Cerrado apresenta heterogeneidade entre áreas (BORGES; SHEPHERD, 2005), caracterizada pelo gradiente savana-floresta com associação particular de espécies (BRIDGEWATER et al., 2004; GOMES et al., 2004). Essa heterogeneidade, geralmente, está condicionada à intensidade de luz e ao regime de perturbações (RICKLEFS, 1996), bem como à natureza geológica e geomorfológica (COLE, 1992), as quais geram diferenças fisionômicas, florísticas e estruturais em resposta às variações edáficas reinantes, como profundidade e umidade do solo e regimes de flutuação do lençol freático (RIBEIRO; WALTER, 2008). As diferenças florísticas independem das distâncias que separam as áreas (FELFILI; SILVA JÚNIOR, 1993).

Nas áreas de Cerrado, diferentes formas de vegetação, variáveis em fisionomia, estrutura e composição florística, podem ser encontradas, em função de características edáficas, da frequência e da intensidade de queimadas e de interferências antrópicas (RUGGIERO et al., 2002). Na área abrangida pelo Cerrado, sobre solos úmidos ou alagáveis, decorrentes da presença de cursos de água, de afloramento do lençol freático ou ainda do acúmulo de água em depressões, estabelecem-se comunidades de caráter florestal, como as matas ciliares e matas de galeria, de caráter campestre, como os campos úmidos ou de caráter misto, como as veredas (ARAÚJO et al., 2002; RIBEIRO; WALTER, 2008).

O Cerrado stricto sensu é o tipo fitofisionômico predominante do bioma e caracteriza-se pela presença de árvores baixas, inclinadas, tortuosas, com ramificações irregulares e retorcidas e, geralmente, com evidências de queimadas. Grande parte dos solos sob essa fitofisionomia pertence às classes Latossolo Vermelho e Latossolo Vermelho-Amarelo. O estrato arbóreo cobre de 5 a $70 \%$ da área, dependendo do subtipo do Cerrado stricto sensu, ou seja, denso, típico, ralo e rupestre. Por Mata de Galeria, entende-se a vegetação florestal que acompanha os rios de pequeno porte e córregos dos planaltos do Brasil Central, formando corredores fechados (galerias) sobre o curso d'água. Geralmente, localiza-se nos fundos dos vales ou nas cabeceiras de drenagem onde os cursos de água ainda não escavaram um canal definitivo e quase sempre é circundada for faixas de vegetação não florestal. Os solos são geralmente Cambissolos, Plintossolos, Argissolos, Gleissolos ou Neossolos (RIBEIRO; WALTER, 2008).

O presente trabalho foi realizado com o compartimento arbóreo em um contínuo de Mata de Galeria/Cerrado sensu stricto em Itumirim, sul de Minas Gerais. O objetivo foi verificar as características fisionômicas e estruturais no fragmento estudado, bem como as variações do substrato, aqui compreendida como o conjunto de variáveis topográficas e edáficas que determinam o status nutricional mineral e o regime de água dos solos.

\section{MATERIAL E MÉTODOS}

\subsection{Descrição da área}

O presente estudo foi conduzido em um fragmento localizado no Município de Itumirim, Minas Gerais (Figura 1A), o qual apresenta um contínuo de Mata de Galeria/ Cerrado stricto sensu. A área possui 3,5 ha (Figura 1B) e encontra-se nas coordenadas de $21^{\circ} 16^{\prime} \mathrm{S}$ e $44^{\circ} 50^{\prime} \mathrm{W}$, com altitude média de $900 \mathrm{~m}$.

O clima regional é de transição entre Cwa e Cwb, de acordo com a classificação climática de Köppen (ANTUNES, 1986), onde Cwa é caracterizado como mesotérmico, com inverno seco e verão chuvoso, no qual a temperatura média do mês mais frio é inferior a $18^{\circ} \mathrm{C}$ e a do mês mais quente é superior a $22^{\circ} \mathrm{C}$, enquanto que no $\mathrm{Cwb}$, a temperatura média do mês mais quente é inferior a $22^{\circ} \mathrm{C}$. Os solos predominantes no local foram classificados, segundo o Sistema Brasileiro de Classificação de Solo da Embrapa (EMPRESA BRASILEIRA DE PESQUISA AGROPECUÁRIA - EMBRAPA, 2006) em Latossolos Vermelho-Amarelos e Cambissolos, derivados da alteração do gnaisse-granítico com predominância dos últimos. A vegetação original da região era composta por um mosaico de diferentes fitofisionomias de cerrados e matas (CARVALHO, 1992; QUEIROZ et al., 1980), as quais foram substituídas por pastagens e culturas agrícolas, restando apenas pequenos fragmentos.

Cerne, Lavras, v. 19, n. 2, p. 213-227, abr./jun. 2013 


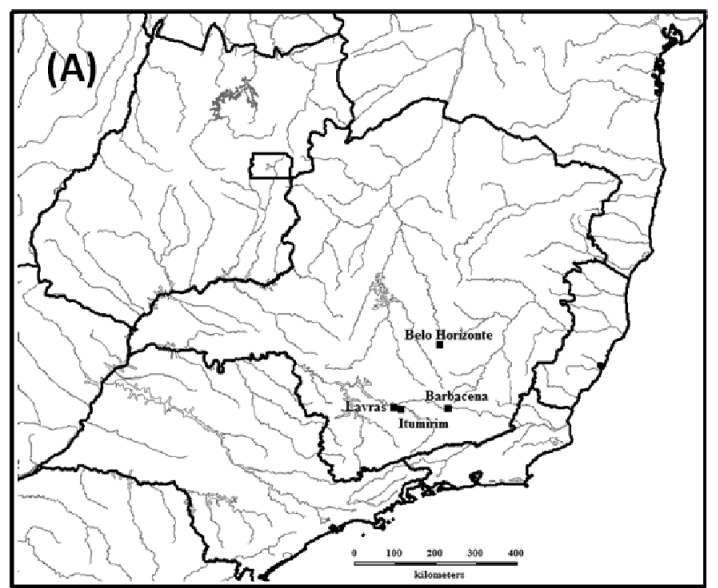

(B)

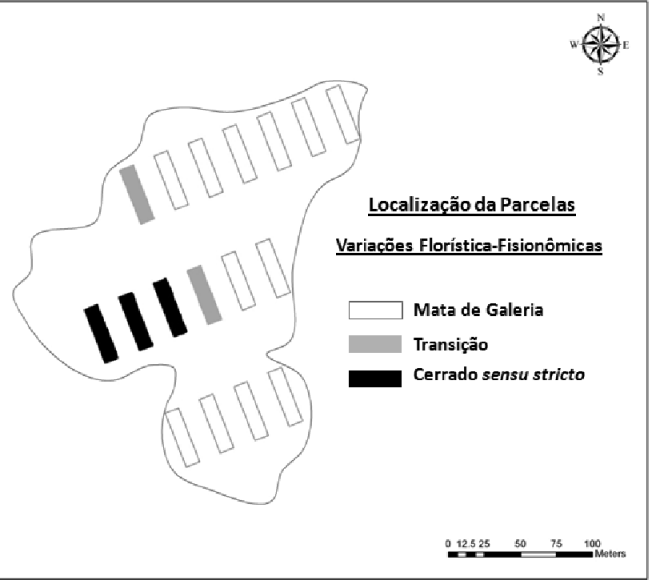

Figura 1 - Localização geográfica do Município de Itumirim, MG (A) e mapa mostrando a localização das 17 parcelas no fragmento estudado neste Município, enfatizando as variações florística-fisionômicas resultando em três padrões de ambientes: Mata de Galeria, $\mathrm{n}=12$; Transição, $\mathrm{n}=2$; Cerrado sensu stricto, $\mathrm{n}=3$ (B).

Figure 1-Geographical location of the town of Itumirim, $M G(A)$ and map showing the location of the 17 plots in the patch studied in this county, emphasizing the floristic-physiognomic variations resulting in three environmetnal patterns: Gallery Forest, $n=12$; Transition Forest, $n=2$; Savana sensu stricto, $n=3$ (B).

\subsection{Levantamento do compartimento arbóreo}

Foram alocadas 17 parcelas de $40 \times 10 \mathrm{~m}$, totalizando uma área amostral de 0,68 ha (19,4\% do fragmento). As parcelas foram distribuídas sistematicamente em três transeções (Figura 1B), onde as distâncias foram de $30 \mathrm{~m}$ entre transeções e $15 \mathrm{~m}$ entre parcelas.

Todos os indivíduos arbóreos vivos e com circunferência a altura de $1,30 \mathrm{~m}$ (CAP) igual ou superior a $15,7 \mathrm{~cm}$, o que equivale a um diâmetro (DAP) de $5,0 \mathrm{~cm}$, no interior das parcelas, foram identificados, e sua circunferência à altura do peito (CAP) foi medida e sua altura total foi estimada. Caules múltiplos foram medidos quando a raiz da soma dos quadrados dos diâmetros $\geq$ $5 \mathrm{~cm}$. Todas as espécies foram coletadas e identificadas por meio de bibliografia especializada, consulta a especialistas e material de herbário, estando as exsicatas dos materiais depositadas no herbário ESAL da Univerisidade Federal de Lavras. As identificações taxonômicas de angiospermas (todas, exceto Cyatheacae e Dicksoniaceae) seguem o sistema Angiosperm Phylogeny Group II (ANGIOSPERM PHYLOGENY GROUP - APG, 2003).

Com base nas variações florística-fisionômicas emergiram padrões de três ambientes resultantes para então classificar as 17 parcelas (Figura 1B) em: Mata de Galeria, $n=12$; Transição, $n=2$; Cerrado sensu stricto, $n=3$. Obtenção das variáveis ambientais - Foi realizado levantamento topográfico com auxílio de um hipsômetro de Suunto para medir a inclinação do terreno. Duas variáveis topográficas foram obtidas a partir dos vértices das parcelas: (a) 'cota média', obtida a partir da média das quatro cotas dos vértices; (b) 'desnível', obtido pela diferença entre as cotas máxima e mínima. Estas foram obtidas como meio de avaliação indireta do regime de água dos solos, conforme adotado por Oliveira-Filho et al. (1990, 1994b).

No interior de cada parcela, foram coletadas, aleatoriamente, cinco amostras simples do solo superficial $(0-20 \mathrm{~cm})$, as quais foram misturadas e homogeneizadas para formar uma amostra composta, com cerca de $500 \mathrm{~g}$ de solo. As amostras foram enviadas para o Laboratório de Análise de Solos do Departamento de Ciências do Solo da UFLA para análises químicas e texturais, realizadas segundo o protocolo da EMBRAPA (1997). As variáveis de solo obtidas foram: $\mathrm{pH}$; teores de $\mathrm{P}, \mathrm{K}^{+}, \mathrm{Ca}^{++}, \mathrm{Mg}^{++} \mathrm{e} \mathrm{Al}{ }^{+++}$; soma de bases (S); saturação por bases (V) e por alumínio (m); e proporções de matéria orgânica, areia, silte e argila. Estrutura fisionômica e diversidade de espécies - A descrição da estrutura fisionômica se baseou nos parâmetros estruturais clássicos: densidade, dominância, tanto absoluta, como relativa, bem como em índice sintético, valor de cobertura (VC), obtido da soma dos valores relativos de densidade e dominância. Foram também utilizadas as seguintes características: densidade de árvores,

Cerne, Lavras, v. 19, n. 2, p. 213-227, abr./jun. 2013 
área basal e distribuição de diâmetros. Foram empregados intervalos de classe diamétrica com amplitudes crescentes para compensar o decréscimo da densidade nas classes de tamanhos maiores (BOTREL et al., 2002).

A diversidade e riqueza de espécies arbóreas na amostra total e nos ambientes foram avaliadas pelos seguintes parâmetros: riqueza de espécies, índices de diversidade de Shannon (H') e de equabilidade de Pielou (J') (BROWER; ZAR, 1984). Também foram calculados os estimadores 'jackknife' de primeira e segunda ordem, os quais projetam o número total de espécies a partir da heterogeneidade da amostra (HELTSHE; FORRESTER, 1983; PALMER, 1991). Os valores de $H^{\prime}$ dos habitats foram comparados pelo teste de $t$ de Hutcheson (ZAR, 1996). As comparações foram feitas aos pares, porque esse teste é o único disponível para comparações estatísticas entre valores de $H^{\prime}$.

Com o intuito de se realizar comparações estruturais entre os ambientes, foi preparada uma matriz baseada nas densidades relativas das espécies em cada área, sendo que, posteriormente, os valores de abundância de espécies, sofreram uma transformação pela expressão $\ln (x+1)$ para compensar os desvios causados pela baixa frequência das densidades mais elevadas (BRAAK, 1995). A ordenação foi realizada por meio de uma análise de correspondência retificada (DCA, Detrendend Correspondence Analysis) (CAUSTON, 1988), sendo utilizado o programa Pc-Ord for Windows versão 4.0 (MCCUNE; MEFFORD, 1999).

\section{RESULTADOS E DISCUSSÃO}

\subsection{Variáveis ambientais}

As cinco classes de solo identificadas no fragmento de transição Mata de Galeria/Cerrado stricto sensu foram: Latossolo Vermelho Amarelo - LVA, fortemente drenado, que se localiza na parte mais alta e plana composta predominantemente por vegetação de Cerrado stricto sensu; Cambissolo Háplico - CX e Neossolo Litólico - RL, ambos bem drenados, que se situam no alto da encosta, onde ocorre a transição do Cerrado stricto sensu para a Mata de Galeria; Cambissolo Húmico - CH, bem a moderadamente drenado, que se localiza na meia encosta; Cambissolo Flúvico - CY, moderadamente drenado, que se situa na base da encosta. Percebe-se que é um fragmento com uma grande heterogeneidade de substrato, sendo que, tal situação pode ser explicada pelo fato dessa área possuir uma topografia bastante irregular formada por vales (associados principalmente a dois pequenos cursos d'água), encostas e topos.

Cerne, Lavras, v. 19, n. 2, p. 213-227, abr./jun. 2013
Os Latossolos Vermelhos Amarelos ocorreram em todas as parcelas do Cerrado stricto sensu, onde, só não foram exclusivos dessa fisionomia, pelo fato de terem ocorrido em uma parcela da Mata de Galeria com topografia similar às áreas de Cerrado stricto sensu. Segundo Ribeiro e Walter (2008), aproximadamente $25 \%$ do bioma Cerrado são dominados por Latossolos Vermelhos Amarelos. Nas parcelas de transição, ocorreram apenas os Cambissolos Háplicos. Já, para as parcelas de Mata de Galeria houve a ocorrência de Cambissolos Flúvicos (7 parcelas), Cambissolos Háplicos (2 parcelas) e, por fim, Cambissolos Húmicos, Neossolos Litólicos e Latossolos Vermelhos Amarelos, todos com ocorrência em uma parcela.

Os resultados das análises química e física do solo para as áreas de Mata de Galeria, transição e Cerrado stricto sensu encontram-se na Tabela 1. Estes permitem classificar o solo das três áreas como de textura média (EMBRAPA, 2006), acidez elevada com $\mathrm{pH}$ entre 4,5 e 5,0 (COMISSÃO DE FERTILIDADE DO SOLO DO ESTADO DE MINAS GERAIS - CFSEMG, 1999) e com altos teores de alumínio. As três fitofisionomias não apresentaram diferenças significativamente distintas entre si.

\subsection{Estrutura e diversidade do compartimento arbóreo}

O levantamento estrutural em todo o fragmento apresentou 1.347 indivíduos que se distribuíram em 39 famílias, 77 gêneros e 102 espécies. A família Fabaceae destacou-se pela maior riqueza de espécies (15) e gêneros (13), representando $14,7 \%$ do total de espécies registradas. Na segunda posição, a família Myrtaceae apresentou 12 espécies seguida das famílias Lauraceae e Rubiaceae, ambas com seis espécies. Na Mata de Galeria, as famílias Fabaceae e Myrtaceae contribuíram ambas com 12 espécies, seguidas por Lauraceae (sete) e Rubiaceae (cinco). De acordo com Leitão-Filho (1987), as famílias Myrtaceae, Lauraceae, Fabaceae, Euphorbiaceae e Rubiaceae são as de maior riqueza nas matas ciliares do Centro-Sul do Brasil. No Cerrado stricto sensu, novamente as famílias Fabaceae e Myrtaceae, ambas com cinco espécies, destacaram-se pela maior riqueza, seguida por Rubiaceae com quatro espécies. Em se tratando da flora lenhosa de Cerrado sentido restrito, famílias como Fabaceae, Vochysiaceae, Myrtaceae, Malpighiaceae e Rubiaceae comumente apresentam altos valores de riqueza florística (AMARAL et al., 2006; ASSUNÇÃO; FELFILI, 2004; FELFILI et al., 2002; MEIRA-NETO; SAPORETTI JUNIOR, 2002; RATTER et al., 2000). Já, na área de transição, a família Myrtaceae, com 10 espécies, foi a que 
apresentou maior riqueza, seguida por Fabaceae (cinco) e Lauraceae (quatro). De maneira geral, o perfil florístico do fragmento estudado apresenta semelhanças com outras florestas semidecíduas baixo-montanas da região centrosul de Minas Gerais, como os estudadas por Botrel et al. (2002), Carvalho et al. (1995), Espírito-Santo et al. (2002), Oliveira-Filho et al. (1994a) e Souza et al. (2003).

Os gêneros que apresentaram maior riqueza florística no fragmento e todos com três espécies foram: Casearia, Eugenia, Machaerium, Myrcia, Ocotea e Protium. Já, os gêneros que contribuíram com os maiores números de indivíduos foram: Protium (256), Tapirira (134), Myrcia (129), Copaifera (110), Myrsine (105) e Eugenia (69).

$\mathrm{Na}$ Tabela 2, apresentam-se os parâmetros estruturais das espécies amostradas nas 17 parcelas. Os indivíduos com DAP $\geq 5 \mathrm{~cm}$ inventariados na amostra (0,68ha), somaram uma área basal de $16,84 \mathrm{~m}^{2}$. Para a Mata de Galeria foram inventariados 0,48ha com 923 indivíduos, totalizando uma área basal de $13,85 \mathrm{~m}^{2}$, que corresponde a $82,2 \%$ da área basal total. As sete espécies verificadas na Mata de Galeria que apresentaram os maiores valores de área basal foram Protium spruceanum, Copaifera langsdorffi, Tapirira obtusa, Protium widgrenii, Machaerium villosum, Luehea candicans e Myrcia tomentosa. Em 0,12ha amostrado de Cerrado stricto sensu, foram registrados 272 indivíduos somando $1,43 \mathrm{~m}^{2}$ de área basal, onde as sete espécies que apresentaram os maiores valores foram Myrsine umbellata, Tapirira obtusa, Myrcia splendens, Rudgea viburnoides, Copaifera langsdorffi, Myrcia tomentosa e Eugenia florida. E, por fim, na área de transição, houve 152 individuos inventariados $\left(1,56 \mathrm{~m}^{2}\right.$ de área basal) em 0,08ha de amostra, sendo que, as sete espécies que obtiveram os maiores valores foram Copaifera langsdorffi, Protium spruceanum, Myrsine umbellata, Tapirira obtusa e Myrcia tomentosa, Duguetia lanceolata e Protium widgrenii.

Tabela 1 - Variáveis do solo superficial $(0-20 \mathrm{~cm})$ e de relevo nas 17 parcelas $(40 \times 10 \mathrm{~m})$ utilizadas para amostrar o continuo Mata de Galeria/Cerrado sensu stricto. Os valores são médias \pm desvios padrão das $\mathrm{n}$ amostras de cada um dos ambientes. As médias são comparadas por testes de $t$ de Student para amostras independentes.

Table 1 - Variables of the surface soil $(0-20 \mathrm{~cm})$ and of relief in the 17 plots $(40 \times 10 \mathrm{~m})$ utilized to sample the Mata de Galerial Savana sensu stricto continuum. The values are means \pm standard deviations of the $n$ samples of each one of the places. The means are compared by Student t tests for independent samples.

\begin{tabular}{|c|c|c|c|c|c|c|c|c|c|c|c|}
\hline \multirow{2}{*}{ Variáveis ambientais } & \multicolumn{3}{|c|}{ Mata de galeria } & \multicolumn{3}{|c|}{ Transição } & \multicolumn{3}{|c|}{ Cerrado } & \multirow{2}{*}{$t$} & \multirow{2}{*}{$P$} \\
\hline & \multicolumn{3}{|c|}{$n=12$} & \multicolumn{3}{|c|}{$n=2$} & \multicolumn{3}{|c|}{$n=3$} & & \\
\hline \multicolumn{12}{|l|}{ Químicas: } \\
\hline $\mathrm{pH} \mathrm{em} \mathrm{H}_{2} \mathrm{O}$ & 4,96 & \pm & 0.24 & 4.85 & \pm & 0.49 & 4.9 & \pm & 0.00 & 0.2 & 0.82 \\
\hline $\mathrm{P}-\operatorname{Mehlich}\left(\mathrm{mg} \cdot \mathrm{dm}^{-3}\right)$ & 2.23 & \pm & 0.77 & 1.95 & \pm & 0.78 & 1.87 & \pm & 0.57 & 0.36 & 0.71 \\
\hline $\mathrm{K}^{+}\left(\mathrm{mg} \cdot \mathrm{dm}^{-3}\right)$ & 77.08 & \pm & 16.01 & 77.00 & \pm & 18.38 & 66.67 & \pm & 15.01 & 0.52 & 0.61 \\
\hline $\mathrm{Ca}^{++}\left(\mathrm{cmolc} . \mathrm{dm}^{-3}\right)$ & 0.53 & \pm & 0.23 & 0.4 & \pm & 0.28 & 0.23 & \pm & 0.06 & 2.29 & 0.14 \\
\hline $\mathrm{Mg}^{++}\left(\mathrm{cmolc} \cdot \mathrm{dm}^{-3}\right)$ & 0.29 & \pm & 0.13 & 0.25 & \pm & 0.21 & 0.13 & \pm & 0.06 & 1.75 & 0.21 \\
\hline $\mathrm{Al}^{+++}\left(\mathrm{cmolc}^{\mathrm{d} \mathrm{dm}^{-3}}\right)$ & 1.52 & \pm & 0.57 & 1.8 & \pm & 0.99 & 1.63 & \pm & 0.15 & 0.23 & 0.8 \\
\hline $\mathrm{SB}$ - soma de bases $\left(\mathrm{cmolc}^{\left.-\mathrm{dm}^{-3}\right)}\right.$ & 1.01 & \pm & 0.38 & 0.85 & \pm & 0.49 & 0.57 & \pm & 0.12 & 1.76 & 0.21 \\
\hline V - saturação de bases (\%) & 15.21 & \pm & 7.86 & 12.75 & \pm & 12.37 & 9.00 & \pm & 2.04 & 0.79 & 0.52 \\
\hline m - saturação de alumínio (\%) & 59.17 & \pm & 15.51 & 65.5 & \pm & 26.16 & 75.33 & \pm & 6.43 & 1.32 & 0.3 \\
\hline Matéria orgânica (dag.kg-1) & 2.81 & \pm & 0.58 & 2.65 & \pm & 0.92 & 2.17 & \pm & 0.31 & 1.48 & 0.26 \\
\hline \multicolumn{12}{|l|}{ Textural: } \\
\hline Areia (\%) & 46.33 & \pm & 9.97 & 45.00 & \pm & 9.9 & 55.33 & \pm & 6.03 & 1.17 & 0.34 \\
\hline Silte (\%) & 24.58 & \pm & 7.35 & 19.5 & \pm & 6.36 & 23.33 & \pm & 4.04 & 0.47 & 0.64 \\
\hline Argila (\%) & 29.08 & \pm & 8.75 & 35.5 & \pm & 3.54 & 21.33 & \pm & 2.31 & 2.07 & 0.16 \\
\hline \multicolumn{12}{|l|}{ Relevo: } \\
\hline Elevação média (m) & 884.93 & \pm & 7.07 & 884.4 & \pm & 5.37 & 887.81 & \pm & 1.17 & 0.27 & 0.77 \\
\hline Desnível (m) & 8.49 & \pm & 2.00 & 7.3 & \pm & 2.55 & 6.17 & \pm & 1.63 & 1.75 & 0.21 \\
\hline
\end{tabular}

Cerne, Lavras, v. 19, n. 2, p. 213-227, abr./jun. 2013 


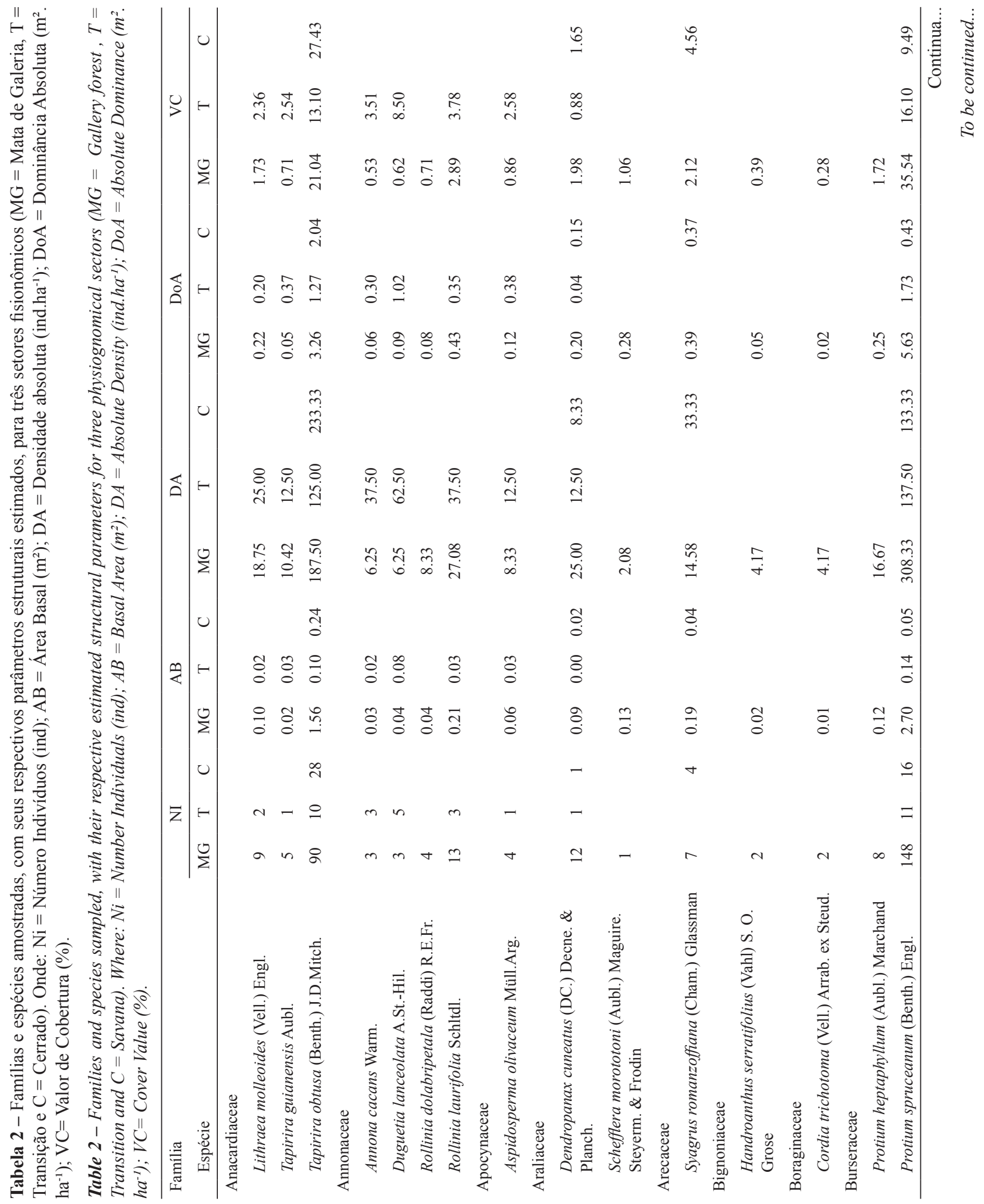

Cerne, Lavras, v. 19, n. 2, p. 213-227, abr./jun. 2013 


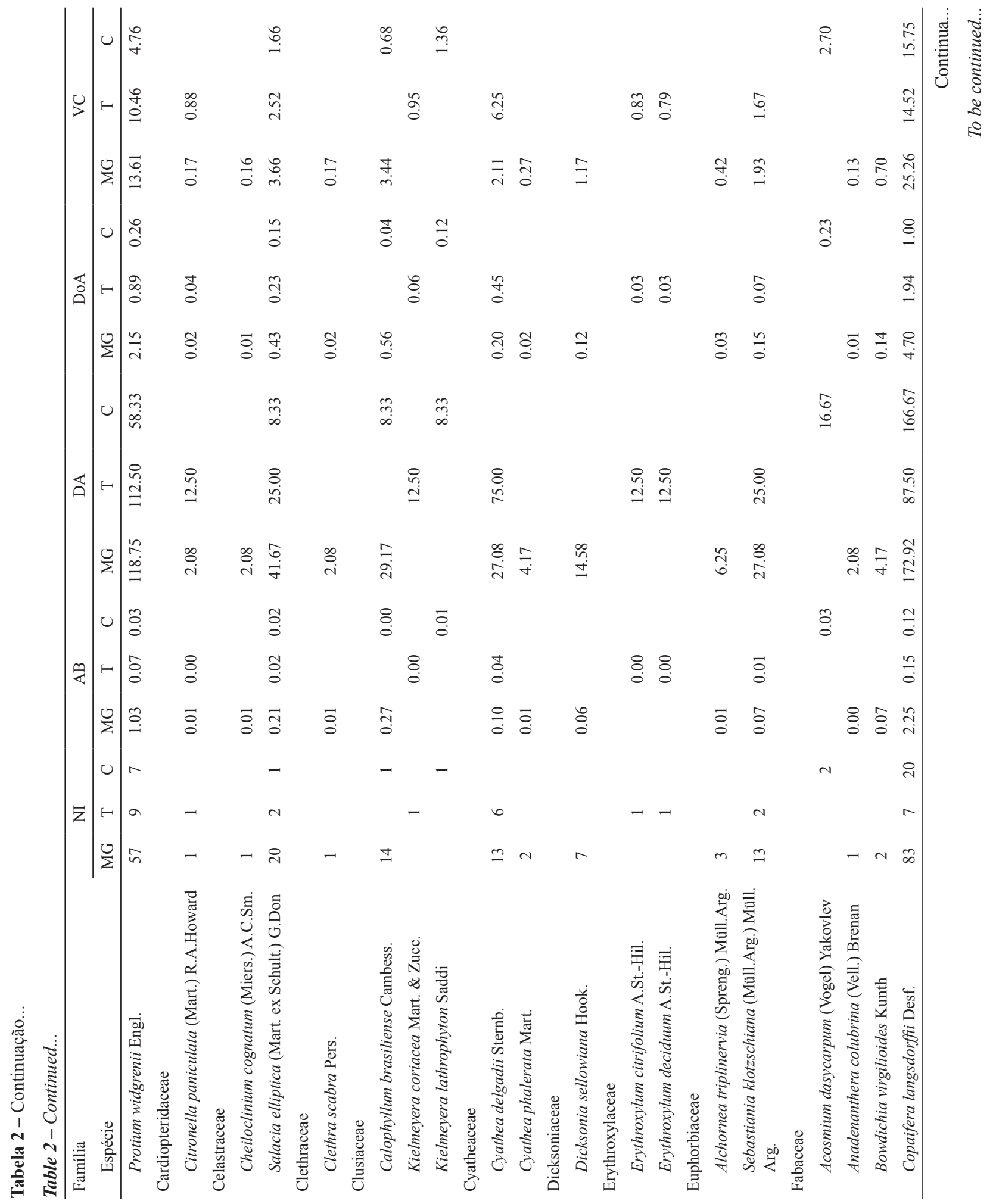

Cerne, Lavras, v. 19, n. 2, p. 213-227, abr./jun. 2013 


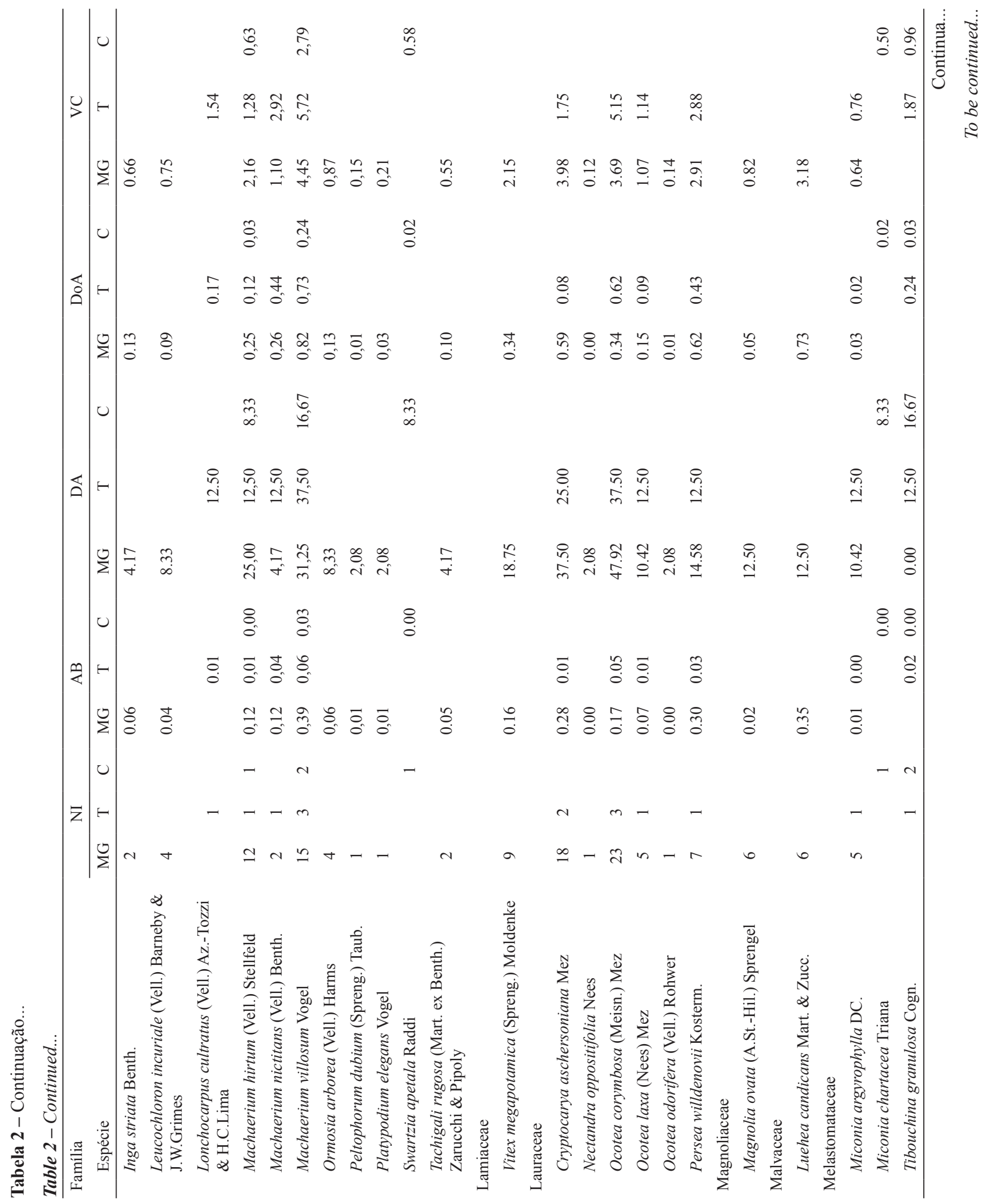

Cerne, Lavras, v. 19, n. 2, p. 213-227, abr./jun. 2013 


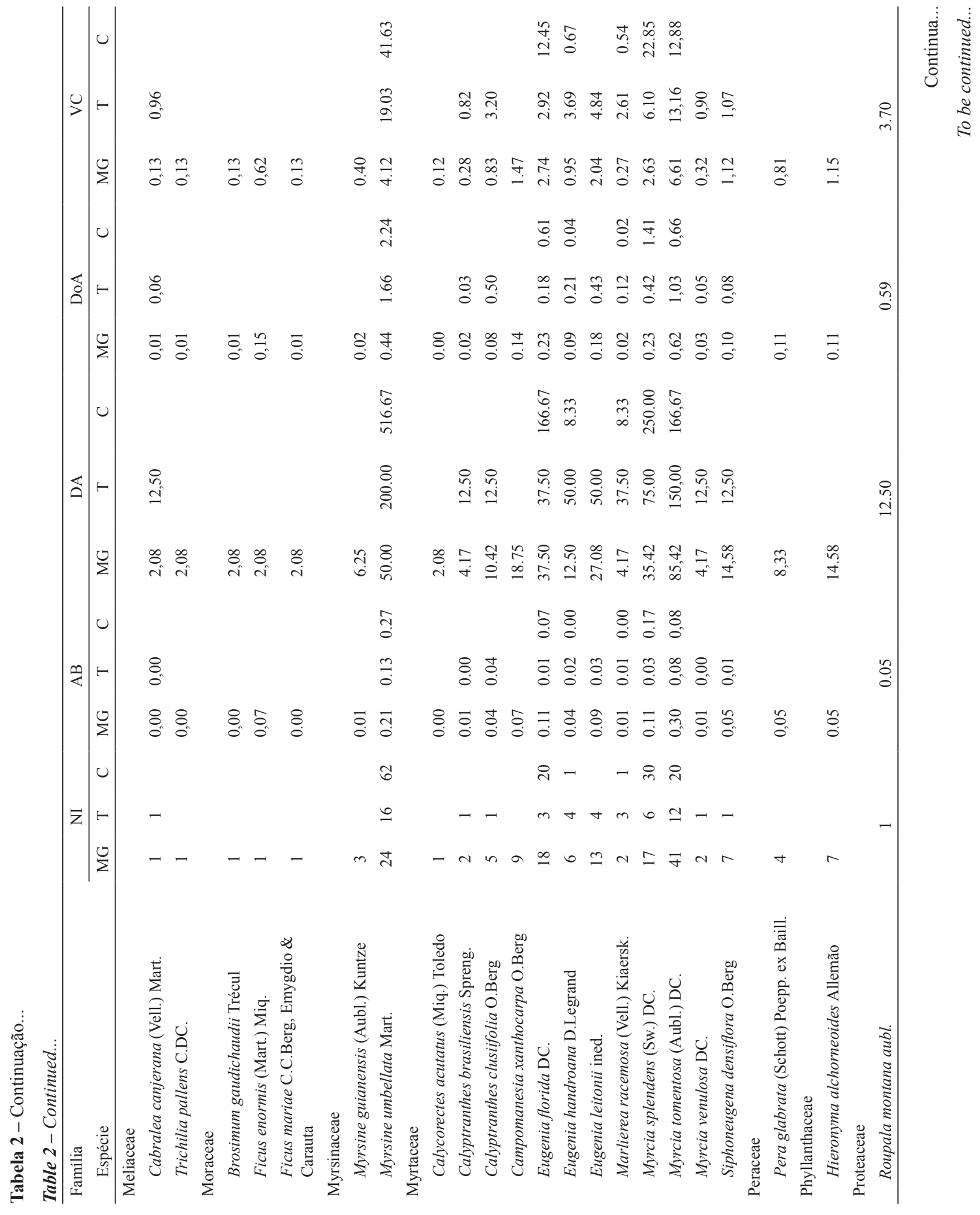

Cerne, Lavras, v. 19, n. 2, p. 213-227, abr./jun. 2013 
Loschi, R. A. et al.

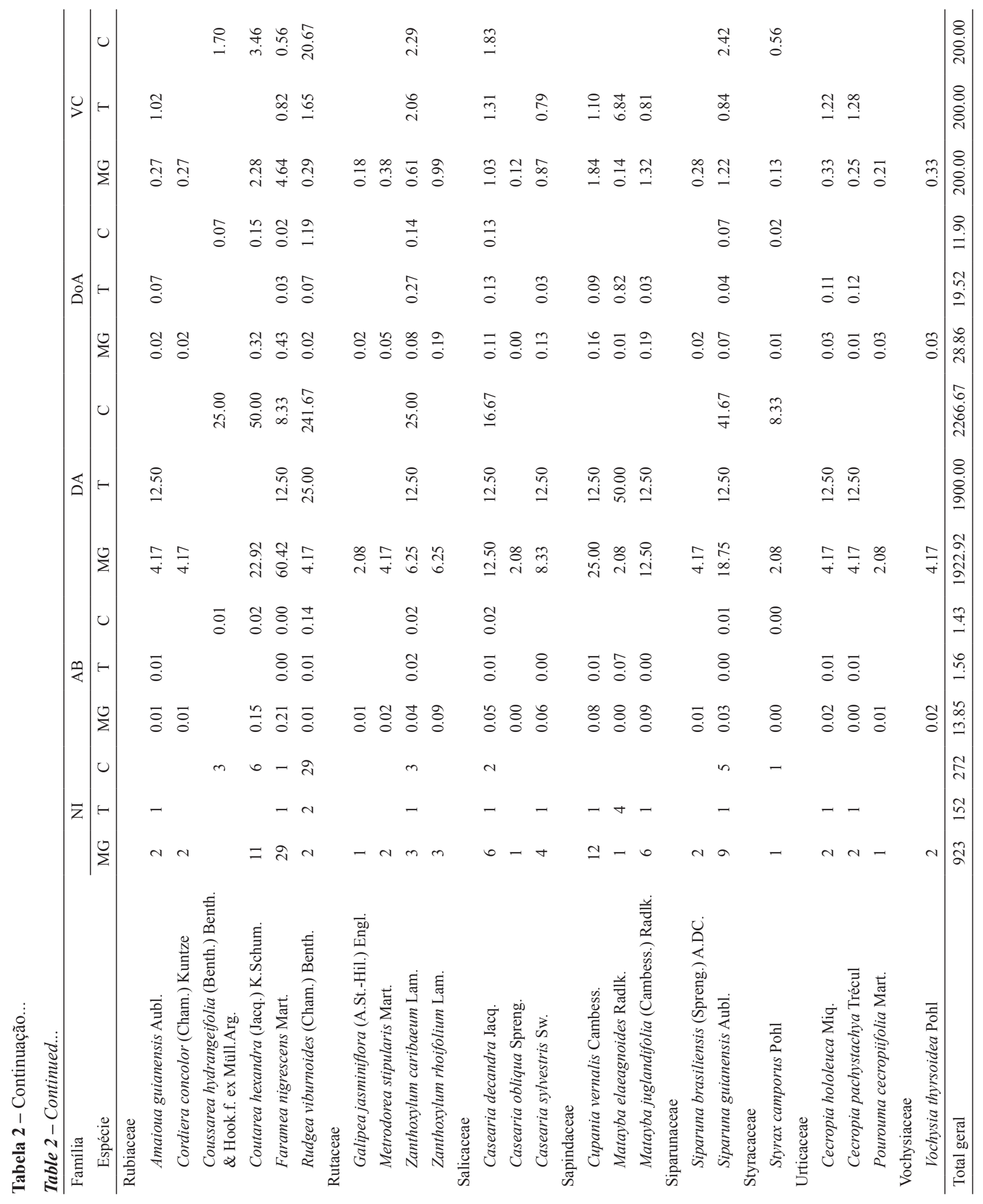

Cerne, Lavras, v. 19, n. 2, p. 213-227, abr./jun. 2013 
As espécies $P$. spruceanum, T. obtusa, $C$. langsdorffii, $P$. widgrenii, M. tomentosa, Faramea nigrescens e $M$. umbellata apresentaram os maiores valores de densidade absoluta na Mata de Galeria. No Cerrado stricto sensu, as sete espécies que obtiveram os maiores valores foram M. umbellata, Myrcia splendens, Rudgea viburnoides, T. obtusa, C. langsdorffi, Eugenia florida e M. tomentosa. Na transição as sete espécies que apresentaram os maiores valores foram $M$. umbellata, M. tomentosa, P. spruceanum, T. obtusa, P. widgrenii, $C$. langsdorffii e Cyathea delgadii.

Com relação à dominância absoluta, as espécies P. spruceanum, C. langsdorffi, T. obtusa, P. widgrenii, Machaerium villosum, Luehea candicans e $M$. tomentosa obtiveram os maiores valores para a Mata de Galeria. Para o Cerrado stricto sensu, foram as seguintes espécies: $M$. umbellata, T. obtusa, M. splendens, $R$. viburnoides, $C$. langsdorffii, M. tomentosa e E. florida. Na transição, as sete espécies que apresentaram os maiores valores foram C. langsdorffii, P. spruceanum, M. umbellata, T. obtusa, M. tomentosa, Duguetia lanceolata e P. widgrenii.
E por fim, as sete espécies que obtiveram as maiores estimativas de valor de cobertura na Mata de Galeria foram $P$. spruceanum, C. langsdorffi, $T$. obtusa, $P$. widgrenii, $M$. tomentosa, $F$. nigrescens e $M$. villosum. No Cerrado stricto sensu, as sete espécies que apresentaram os maiores valores foram M. umbellata, T. obtusa, $M$. splendens, $R$. viburnoides, $C$. langsdorffii, $M$. tomentosa $\mathrm{e}$ E. florida. Na transição, as sete espécies que apresentaram os maiores valores foram $M$. umbellata, $P$. spruceanum, C. langsdorffi, $M$. tomentosa, T. obtusa, P. widgrenii e Duguetia lanceolata.

Para todos os parâmetros apresentados, as espécies P. spruceanum e M. umbellata foram as mais importantes no levantamento, respectivamente para as áreas de Mata de Galeria e Cerrado stricto sensu. Na área de transição, a espécie C. langsdorffii obteve os maiores valores de área basal e dominância absoluta; já com relação à densidade absoluta e valor de cobertura foi a espécie $M$. umbellata.

As distribuições de densidade por classes de diâmetro (Figura 2) mostram que o Cerrado stricto sensu apresenta os maiores valores de densidade para a menor

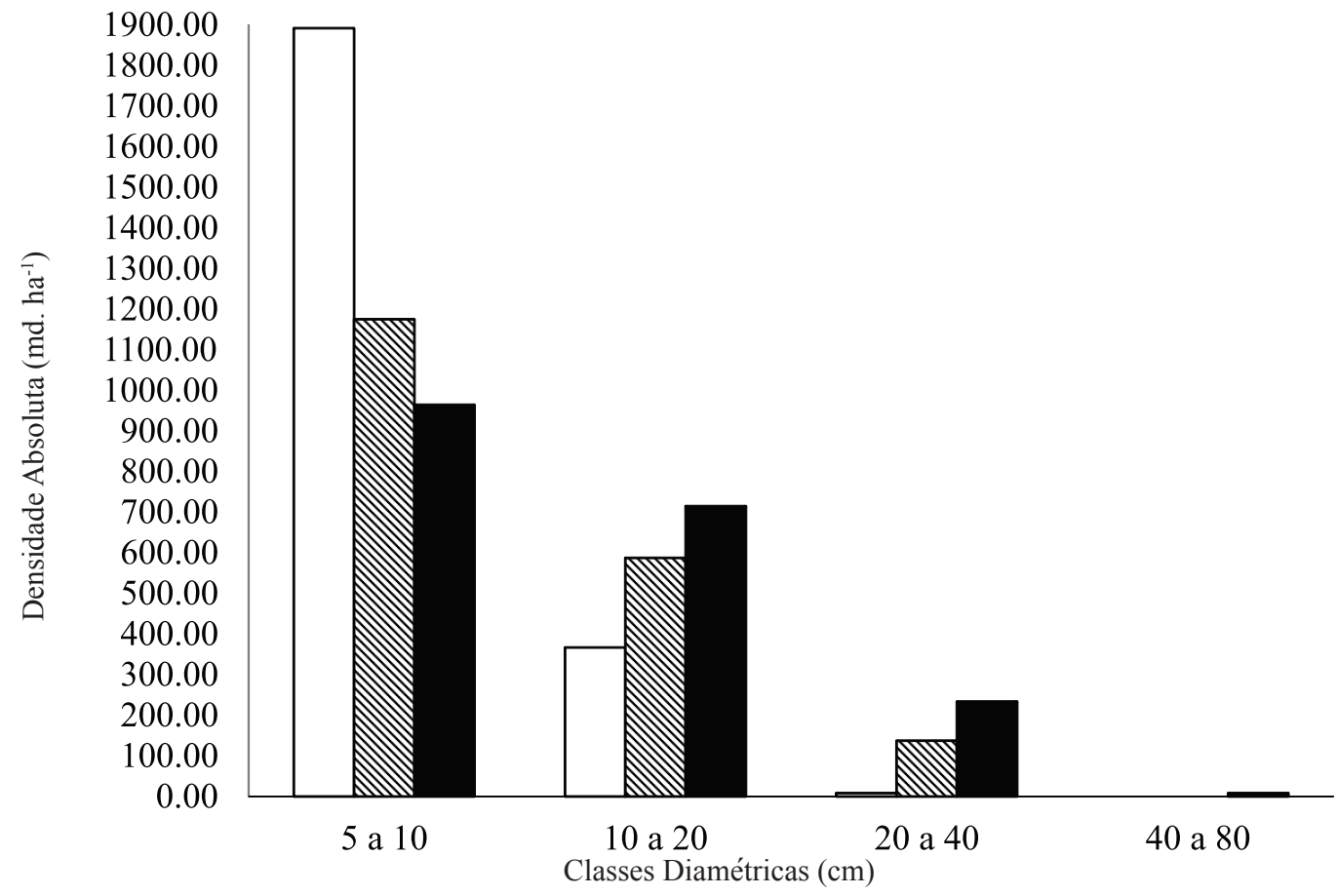

Figura 2 - Distribuição da densidade de árvores $\geq 5 \mathrm{~cm}$ de DAP em classes de diâmetro nas 17 parcelas amostradas no Cerrado

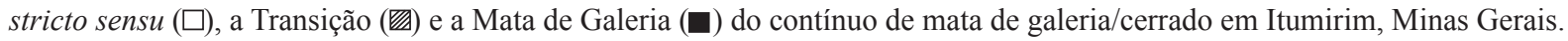

Figure $2-$ Distribution of the density of trees $\geq 5 \mathrm{~cm}$ of BHD in diameter classes in the 17 plots sampled in the Savana stricto sensu

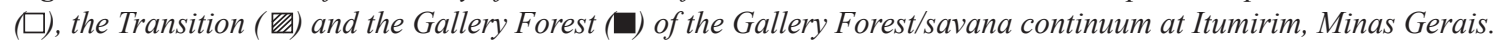

Cerne, Lavras, v. 19, n. 2, p. 213-227, abr./jun. 2013 
classe de DAP $(5-10 \mathrm{~cm})$, sendo, significativamente, superior aos outros dois ambientes $(\mathrm{t}=8,614 ; p=0,013)$. Já, para as classes de 10-20 e 20-40 cm observa-se que a Mata de Galeria apresenta os maiores valores de densidade seguidas da transição e Cerrado stricto sensu, contudo observam-se valores significativos apenas para a primeira classe $(\mathrm{t}=6,723 ; p=0,035)$. Na maior classe de DAP $(40-80 \mathrm{~cm})$, os indivíduos verificados foram exclusivos das parcelas da Mata de Galeria.

Os índices de diversidade de Shannon (H') e os índices de equabilidade de Pielou (J') para os três ambientes foram de 3,57, 3,51 e 2,58 e 0,79, 0,88 e 0,77 , respectivamente, para as áreas de Mata de Galeria, transição e Cerrado stricto sensu. O valor de H' foi maior na Mata de Galeria e menor no Cerrado stricto sensu. $\mathrm{O}$ valor do índice de diversidade de Shannon (H') foi baixo quando comparado com outros levantamentos em áreas de Cerrado sensu stricto (ASSUNÇÃO; FELFILI, 2004; FIDELIS; GODOY, 2003; SAPORETTI-JÚNIOR et al., 2003), que em geral apresentam o H' em torno de 3,00. Isso, provavelmente, resulta da distribuição não homogênea de espécies na área, pela abundância de algumas poucas espécies, como a M. umbellata, $M$. splendens, $R$. viburnoides e T. obtusa. De acordo com Guedes (1988), baixos índices de diversidade estão associados a características pedológicas e perturbações antrópicas.

Diversos fatores de difícil controle podem ser relacionados à variação da riqueza entre as fisionomias do presente estudo. Entre elas, podem ser citadas a fisionomia vegetacional e o ambiente a ela relacionado e o histórico de perturbações. De acordo com Oliveira-Filho et al. (1990), riqueza de espécies relativamente elevada é característica comum em florestas ciliares, por uma heterogeneidade ambiental comumente superior à de florestas de terra firme próximas.

Comparando a composição florística entre os três grupos, conforme o diagrama de Venn (Figura 3), observa-se nas parcelas alocadas no Cerrado stricto sensu que cinco das 29 espécies (17\%) registradas foram exclusivas do Cerrado (Acosmium dasycarpum, Coussarea hydrangeifolia, Kielmeyera lathrophyton, Miconia chartacea e Swartzia apetala). Também foram registradas cinco espécies exclusivas da área de transição (Erythroxylum citrifolium, Erythroxylum deciduum, Kielmeyera coriácea, Lonchocarpus cultratus e Roupala montana), representando $9 \%$ de um total de 53 espécies. E,

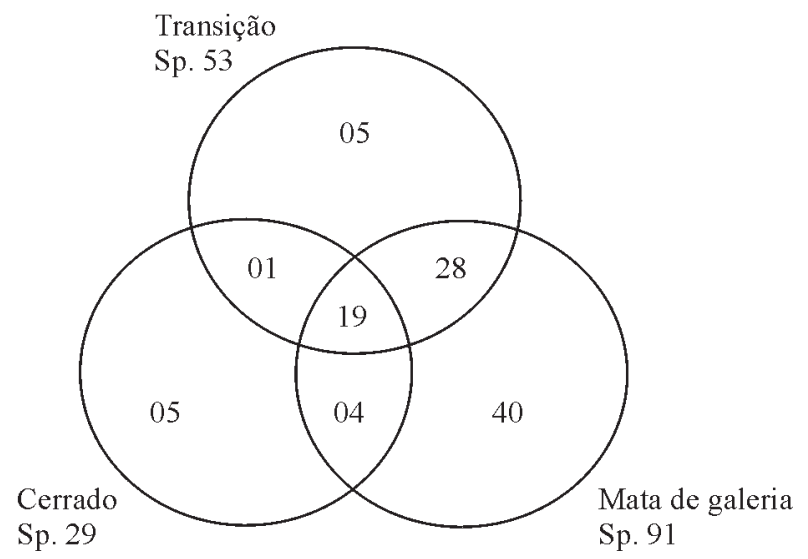

Figura 3 - Diagrama de Venn produzido a partir do número de espécies compartilhadas e exclusivas da Mata de Galeria, Cerrado sensu stricto e Transição do contínuo de Mata de Galeria/Cerrado em Itumirim, Minas Gerais.

Figure 3 - Venn Diagram produced from the number of species shared and unique to the Gallery Forest, Savana sensu stricto and Transition of the Gallery Forest/Savana in Itumirim continuum in Minas Gerais.

por fim, 40 das 91 espécies (44\%) ocorrentes nas parcelas de Mata de Galeria foram exclusivas dessa fisionomia. A diferenciação entre os três grupos está provavelmente relacionada à topografia, juntamente com a umidade do solo. A influência da umidade do solo na distribuição das espécies arbóreas e na formação das fisionomias em florestas tropicais tem sido enfatizada por vários autores (BASTNET, 1992; BERG; OLIVEIRA-FILHO, 1999; BOTREL et al., 2002; CLARK et al., 1998; METZGER et al., 1997; OLIVEIRA-FILHO et al., 1994b). Alguns fatores, tais como, disponibilidade de água e teor de nutrientes nos solos, aliados ao clima, profundidade do lençol freático e fogo, têm sido considerados, para muitos autores, como sendo os principais determinantes do Cerrado (EITEN, 1994; OLIVEIRA-FILHO; RATTER, 1995; RIBEIRO; WALTER, 2008).

As espécies em comum entre as matas e os cerrados evidenciam a importante contribuição desse domínio vegetacional circundante para a flora da mata de galeria estudada e ratifica as observações de Oliveira-Filho e Ratter (1995) de que muitas espécies generalistas são compartilhadas por matas de galeria e cerrados.

A análise de correspondência retificada (DCA) (Figura 4) apresentou autovalores baixos para os dois primeiros eixos de ordenação $(0,316$ e 0,237$)$, indicando gradientes curtos, ou seja, a maioria das

Cerne, Lavras, v. 19, n. 2, p. 213-227, abr./jun. 2013 


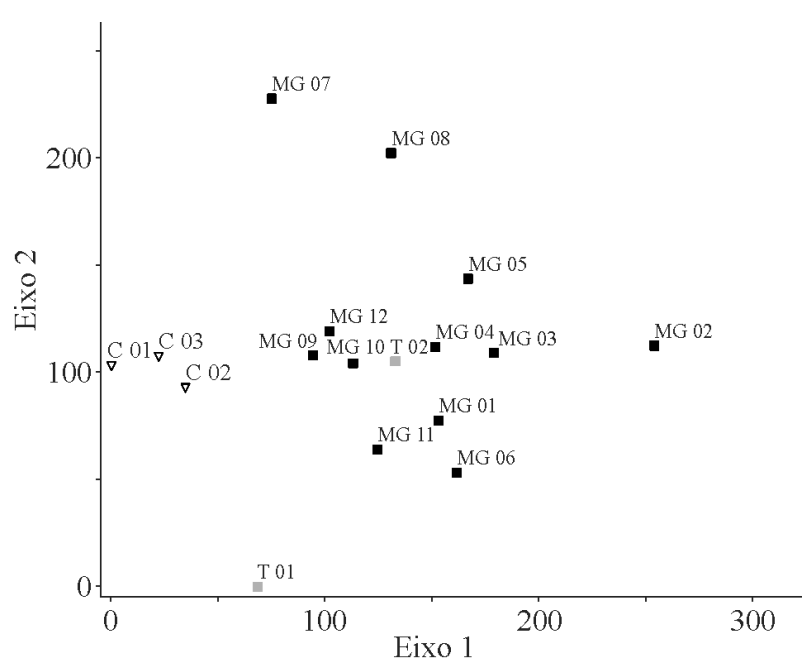

Figura 4 - Diagramas de ordenação nos dois primeiros eixos da análise de correspondência retificada (DCA) dos dados estruturais de três fitofisionomias de um contínuo de Mata de Galeria/ Cerrado em Itumirim, Minas Gerais. Os símbolos correspondem: Cerrado sensu stricto $(\nabla)$, Transição $(\square)$ e Mata de Galeria ( $\square$ ).

Figure 4 - Ordination diagrams in the two first axes of the rectified correspondence analysis (DCA) of the structural data of three phytophysiognomies in a continuum of Gallery Forest/ Savana in Itumirim, Minas Gerais. The symbols are: Savana sensu stricto $(\nabla)$, Transition $(\square)$ and gallery Forest $(\square)$.

espécies está distribuída por todo o gradiente e apenas uma minoria concentra-se em setores particulares do gradiente (BRAAK, 1995). Isto sugere que os três ambientes formam um grupo relativamente coeso, com muitas espécies em comum, como já foi demosntrado no diagrama de Venn (Figura 3). Contudo, podem ser discriminados dois agrupamentos no diagrama da DCA: o Agrupamento 1 contém apenas as três parcelas pertencentes ao Cerrado stricto sensu, situado à esquerda do primeiro eixo de ordenação; e o Agrupamento 2 reúne as demais parcelas amostradas abrangendo os ambientes de Mata de Galeria e transição. Percebese que as parcelas pertenentes ao ambiente transição tiveram comportamento diferenciado, a saber: T01 se aproximando mais das amostras pertencentes ao Cerrado sensu stricto, enquanto que T02 assemelhou-se com a Mata de Galeria. Tal comportamento é resultado das variações do relevo, com possíveis implicações na capacidade de drenagem do solo, ou ainda algum deslizamento parcial da área de cerrado, na medida em que na região processos erosivos importantes são observados.

\section{CONCLUSÕES}

Os solos das áreas de Mata de Galeria, transição e Cerrado stricto sensu apresentaram textura média, acidez elevada e altos teores de alumínio, onde as variações do relevo, refletindo na capacidade de drenagem do solo, foram, provavelmente, o principal fator responsável pela diferenciação entre os três grupos.

A maior e menor riqueza de espécies foi observada, respectivamente, na Mata de Galeria e no Cerrado stricto sensu, sendo que o valor do índice de diversidade de Shannon (H') foi baixo para os três ambientes.

A análise de correspondência retificada (DCA) sugere que os três ambientes formam um grupo relativamente coeso, com muitas espécies em comum. No entanto, mostrou tendência de separação com dois agrupamentos no diagrama da DCA: de um lado, as parcelas de Cerrado stricto sensu, situado a esquerda do primeiro eixo de ordenação; do outro, as demais parcelas amostradas, abrangendo os ambientes de Mata de Galeria e transição.

\section{REFERÊNCIAS}

AMARAL, A. G.; PEREIRA, F. F. O.; MUNHOZ, C. B. R. Fitossociologia de uma área de cerrado rupestre na Fazenda Sucupira, Brasília, DF. Cerne, Lavras, v. 12, n. 4, p. 350-359, out./dez. 2006.

ANGIOSPERM PHYLOGENY GROUP II. An update of the Angiosperm Phylogeny Group classification for the orders and families of flowering plants: APG II. Botanical Journal of the Linnean Society, London, v. 141, n. 4, p. 399-436, Apr. 2003.

ANTUNES, F. Z. Caracterização climática do Estado de Minas Gerais. Informe Agropecuário, Belo Horizonte, v. 12, n. 138, p. 9-13, jun. 1986.

ARAúJo, G. M.; BARbosA, A. A. A.; ARAntes, A. A.; AMARAL, A. F. Composição florística de veredas no Município de Uberlândia, MG. Revista Brasileira de Botânica, São Paulo, v. 25, n. 4, p. 475-493, 2002.

ASSUNÇÃO, S. L.; FELFILI, J. M. Fitossociologia de um fragmento de cerrado sensu stricto na APA do Paranoá, DF, Brasil. Acta Botanica Brasilica, São Paulo, v. 18, n. 4, p. 903-909, 2004.

BERG, E. van den; OLIVEIRA-FILHO, A. T. Spatial partitioning among tree species within an area of tropical montane gallery forest in south-eastern Brazil. Flora, Jena, v. 194, n. 2/3, p. 249266, May 1999.

Cerne, Lavras, v. 19, n. 2, p. 213-227, abr./jun. 2013 
BRAAK, C. J. F. ter. Ordination. In: JONGMAN, R. H. G.; BRAAK , C. J. F. ter; TONGEREN, O. F. R. van (Ed.). Data analysis in community and landscape ecology. Cambrigde: Cambridge University, 1995. p. 91-173.

BASNET, K. Effect of topography on the pattern of tree in Tabonuco (Dacryodes exelsa) dominanted rain forest of Puerto Rico. Biotropica, Washington, v. 24, n. 1, p. 31-42, 1992.

BORGES, H. B. N.; SHEPHERD, G. J. Flora e estrutura do estrato lenhoso numa comunidade de Cerrado em Santo Antônio do Leverger, MT, Brasil. Revista Brasileira de Botânica, São Paulo, v. 28, n. 1, p. 61-74, jan./mar. 2005.

BOTREL, R. T.; OLIVEIRA-FILHO, A. T.; RODRIGUES, L. A.; CURI, N. Influência do solo e topografia sobre as variações da composição florística e estrutura da comunidade arbóreoarbustiva de uma floresta estacional semidecidual em Ingaí, MG. Revista Brasileira de Botânica, São Paulo, v. 25, n. 2, p. 195-213, jun. 2002.

BRIDGEWATER, S.; RATTER, J. A.; RIBEIRO, J. F. Biogeografic patterns, B-diversity and dominance in the cerrado biome of Brazil. Biodiversity and Conservation, London, v. 13, n. 12, p. 2295-2318, 2004.

BROWER, J. E.; ZAR, J. H. Field and laboratory methods for general ecology. $2^{\text {nd }}$ ed. Dubuque: W. C. Brown, 1984. 225 p.

CARVALHO, D. A. Flora fanerogâmica de campos rupestres da Serra da Bocaina, Minas Gerais: caracterização e lista de espécies. Ciência e Prática, Lavras, v. 16, n. 1, p. 97-122, jan./ jun. 1992.

CARVALHO, D. A.; OLIVEIRA-FILHO, A. T.; VILELA, E. A.; GAVILANES, M. L. Estrutura fitossociológica de mata ripária do alto Rio Grande: Bom Sucesso, Estado de Minas Gerais. Revista Brasileira de Botânica, São Paulo, v. 18, n. 1, p. 39-49, jan. 1995.

CAUSTON, D. R. An introduction to vegetation analysis, principles and interpretation. London: Unwin Hyman, 1988. $342 \mathrm{p}$.

CLARK, D. B.; CLARK, D. A.; READ, J. M. Edaphic variation and the mesoscale distribution of tree species in a neotropical rain forest. Journal of Ecology, Oxford, v. 86, p. 101-112, 1998.

Cerne, Lavras, v. 19, n. 2, p. 213-227, abr./jun. 2013
COLE, M. M. Influence of physical factors on the nature and dynamics of forest-savanna boundaries. In: FURLEY, P. A.; PROCTOR, J.; RATTER, J. A. (Ed.). Nature and dynamics of forest-savanna boundaries. London: Chapman e Hall, 1992. p. 63-75.

COMISSÃO DE FERTILIDADE DO SOLO DO ESTADO DE MINAS GERAIS. Recomendações para o uso de corretivos e fertilizantes em Minas Gerais: $5^{\text {a }}$ aproximação. Viçosa, MG, 1999. $359 \mathrm{p}$.

EITEN, G. Brazilian "Savannas". In: HUNTLEY, B. J.; WALKER, B. H. (Ed.). Ecology of tropical savannas. Berlin: Springer-Verlag, 1982. p. 25-47.

EITEN, G. Vegetação do cerrado. In: PINTO, M. N. (Ed.). Cerrado: caracterização, ocupação e perspectivas. 2. ed. Brasília: UNB, 1994. p. 7-73.

EMPRESA BRASILEIRA DE PESQUISA AGROPECUÁRIA. Manual de métodos de análises de solo. 2. ed. Rio de Janeiro, 1997. 412 p.

EMPRESA BRASILEIRA DE PESQUISAAGROPECUÁRIA. Sistema brasileiro de classificação dos solos. 2. ed. Rio de Janeiro, 2006. 306 p.

ESPÍRITO-SANTO, F. D. B.; OLIVEIRA-FILHO, A. T.; MACHADO, E. L. M.; SOUZA, J. S.; FONTES, M. A. L.; MARQUES, J. J. G. S. M. Variáveis ambientais e a distribuição de espécies arbóreas em um remanescente de floresta estacional semidecidual montana no campus da Universidade Federal de Lavras (UFLA), MG. Acta Botanica Brasílica, Brasília, v. 16, p. $331-356,2002$.

FELFILI, J. M.; NOGUEIRA, P. E.; SILVA JÚNIOR, M. C.; MARIMON, B. S.; DELITTI, W. B. C. Composição florística e fitossociológica de um cerrado sensu stricto em Água Boa, MT. Acta Botanica Brasilica, Porto Alegre, v. 16, n. 1, p. 103-112, 2002 .

FELFILI, J. M.; SILVA JÚNIOR, M. C. A comparative study of cerrado (sensu stricto) vegetation in Central Brazil. Journal of Tropical Ecology, Cambridge, v. 9, p. 277-289, 1993.

FIDELIS, A. T.; GODOY, S. A. P. Estrutura de um cerrado strico sensu na Gleba Cerrado Pé-de-Gigante, Santa Rita do Passa Quatro, SP. Acta Botanica Brasilica, Porto Alegre, v. 17, n. 4, p. 531-539, 2003. 
GOMES, B. Z.; MARTINES, F. R.; TAMASHIRO, J. Y. Estrutura do cerradão e da transição entre cerradão e floresta paludícola num fragmento da International Paper do Brasil Ltda., em Brotas, SP. Revista Brasileira de Botânica, São Paulo, v. 27, n. 2, p. 249-262, 2004.

GUEDES, R. R. Composição florística e estrutura de um trecho de mata perturbada de baixada no município de Magé, Rio de Janeiro. Arquivo Jardim Botânico do Rio de Janeiro, Rio de Janeiro, v. 29, p. 155-200, 1988.

HELTSHE, J. F.; FORRESTER, N. E. Estimating species richness using the jackknife procedure. Biometrics, Washington, v. 39, p. 1-12, 1983.

LEITÃO-FILHO, H. F. Considerações sobre a florística de florestas tropicais e sub-tropicais do Brasil. IPEF, Piracicaba, v. 35, p. $41-46,1987$.

MCCUNE, B.; MEFFORD, M. J. PC-ORD version 4.14 multivariate analysis of ecological data. Glenden Beach: $\mathrm{MjM}$, 1999. 1 CD-ROM.

MEIRA-NETO, J. A. A.; SAPORETTI JUNIOR, A. W. Phytosociological parameters of a cerrado in Serra do Cipó national park, Minas Gerais, Brazil. Revista Árvore, Viçosa, v. 26, n. 5, p. 645-648, out. 2002.

METZGER, J. P.; BERNACCI, L. C.; GOLDENBERG, R. Pattern of tree species diversity in riparian forest fragments of different widths (SE Brazil). Plant Ecology, Dordrecht, v. 133, n. 2, p. 135-152, 1997.

OLIVEIRA-FILHO, A. T.; RATTER, J. A. A study of the origin of central Brazilian forests by the analysis of plant species distribution patterns. Edinburgh Journal of Botany, Edinburgh, v. 52, n. 2, p. 141-194, 1995.

OLIVEIRA-FILHO, A. T.; RATTER, J. A.; SHEPHERD, G. J. Floristic composition and community structure of a Brazilian gallery forest. Flora, London, v. 184, n. 2, p. 103-117, 1990.

OLIVEIRA-FILHO, A. T.; SCOLFORO, J. R.; MELLO, J. M. Composição florística e estrutura comunitária de um remanescente de floresta semidecídua montana em Lavras, MG. Revista Brasileira de Botânica, Rio de Janeiro, v. 17, n. 2, p. 159-174, dez. 1994a.
OLIVEIRA-FILHO, A. T.; VILELA, E. A.; CARVALHO, D. A.; GAVILANES, M. L. Effects of soils and topography on the distribution of tree species in a tropical riverine forest in southeastern Brazil. Journal of Tropical Ecology, Aberdeen, v. 10, n. 4, p. 483-508, 1994 b.

PALMER, M. W. Estimating species richness: the second-order jackknife estimator reconsidered. Ecology, Durham, v. 72, p. 1512-1513, 1991.

QUEIROZ, R.; SOUZA, A. G.; SANTANA, P.; ANTUNES, F.Z.; FONTES, M. Zoneamento agroclimático do Estado de Minas Gerais. Belo Horizonte: EPAMIG, 1980. 114 p.

RATTER, J. A.; BRIDGEWATER, S.; RIBEIRO, J. F.; DIAS, T. A. B.; SILVA, M. R. Estudo preliminar da distribuição das espécies lenhosas da fitofisionomia cerrado sentido restrito nos estados compreendidos pelo bioma Cerrado. Boletim do Herbário Ezechias Paulo Heringer, Brasília, v. 5, p. 5-43, 2000.

RIBEIRO, J. F.; WALTER, B. M. T. As Principais fitofisionomias do bioma Cerrado. In: SANO, S. M.; ALMEIDA, S. P.; RIBEIRO, J. F. (Ed.). Cerrado: ecologia e flora. Brasília: EMBRAPA Informações Tecnológicas, 2008. p. 152-212.

RICKLEFS, R. E. A economia da natureza: um livro-texto em ecologia básica. Rio de Janeiro: Guanabara Koogan, 1996. 470 p.

RUGGiero, P. G. C.; BATALHA, M. A.; PIVELLO, V. R.; MEIRELLES, S. T. Soil vegetation relationships in cerrado (Brazilian savanna) and semideciduous forest, Southeastern Brazil. Plant Ecology, Wageningen, v. 160, n. 1, p. 1-16, 2002.

SAPORETTI-JÚNIOR, A. W.; MEIRA-NETO, J. A. A.; ALMADO, R. P. Fitossociologia de cerrado sensu stricto no município de Abaeté-MG. Revista Árvore, Viçosa, v. 27, n. 3, p. 413-419, maio/jun. 2003.

SOUZA, J. S.; ESPÍRITO-SANTO, F. D. B.; FONTES, M. A. L.; OLIVEIRA FILHO, A. T.; BOTEZELLI, L. Análise das variações florísticas e estruturais da comunidade arbórea de um fragmento de floresta semidecídua às margens do rio Capivarí, Lavras, MG. Revista Árvore, Viçosa, v. 27, p. 185-206, 2003.

ZAR, J. R. Biostatistical analysis. $3^{\text {rd }}$ ed. New Jersey: Prentice Hall, 1996.

Cerne, Lavras, v. 19, n. 2, p. 213-227, abr./jun. 2013 
